INDEPENDENT JOURNAL OF MANAGEMENT \& PRODUCTION (IJM\&P)

http://www.ijmp.jor.br

v. 7, n. 1, January - March 2016

ISSN: 2236-269X

DOI: 10.14807/ijmp.v7i1.369

\title{
PRINCIPAL COMPONENTS IN MULTIVARIATE CONTROL CHARTS APPLIED TO DATA INSTRUMENTATION OF DAMS
}

\author{
Emerson Lazzarotto \\ Universidade Estadual do Oeste do Paraná - UNIOESTE, Brazil \\ E-mail: emerson.lazzarotto@gmail.com
}

Liliana Madalena Gramani

Universidade Federal do Paraná, Brazil

E-mail: I.gramani@gmail.com

Anselmo Chaves Neto

Universidade Federal do Paraná, Brazil

E-mail: anselmo@ufpr.br

Luiz Albino Teixeira Junior Universidade Federal da Integração Latino Americana - UNILA, Brazil

E-mail: luiz.a.t.junior@gmail.com

Submission: 11/09/2015

Accept: 26/09/2015

\section{ABSTRACT}

A high number of instruments that assess various quality characteristics of interest that have an inherent variability monitors hydroelectric plants. The readings of these instruments generate time series of data on many occasions have correlation. Each project of a dam plant has characteristics that make it unique. Faced with the need to establish statistical control limits for the instrumentation data, this article makes an approach to multivariate statistical analysis and proposes a model that uses principal components control charts and statistical $T^{2}$ and $Q$ to explain variability and establish a method of monitoring to control future observations. An application for section $E$ of the Itaipu hydroelectric plant is performed to validate the model. The results show that the method used is appropriate and can help identify the type of outliers, reducing false alarms and reveal instruments that have higher contribution to the variability.

Keywords: Statistical quality control; multivariate control charts; principal component analysis; dam safety. 


\section{INTRODUCTION}

The control chart is one of statistical quality control techniques most used and can be very useful in controlling the instrumentation of a dam. The facility of online supplying of data with high frequency provides a huge mass of data that generates a series of control charts. However, it is necessary to interpret these data to produce additional knowledge beyond simple time series data.

Hotelling (1947) introduced multivariate control charts at the time of the Second World War and, from the development of computers that enabled its implementation, had great development. Its use has spread because of the need for quality control of several variables not is adequately treated with univariate tools such as Shewhart control charts, especially when there is correlation between variables. Once the variables do not behave independently of one another, they should be considered together and not separately (MASON; YOUNG, 2002).

A typical control chart plots the averages of measurements of a quality characteristic as a function of time. The chart has a center line that represents the target of the quality characteristic value if there were no variability and the other two lines, the upper and lower control limits that are determined statistically. Such control charts are called Shewhart control charts (MONTGOMERY, 2013).

There are several techniques to address the multivariate control type Shewhart charts, among them the $T^{2}$ charts, cumulative sums (CUSUM), exponentially weighted moving average (EWMA), principal component analysis (PCA), partial least squares (PLS), and non-parametric or distribution free techniques (BERSIMIS; PSARAKIS; PANARETOS, 2007). The PCA can be extremely useful in quality control applications, transforming a set of correlated variables into a new set of uncorrelated variables that can be easier to be monitored via control charts (JACKSON, 1991).

The monitoring of structural behavior of hydroelectric dams because the economic, social and environmental importance of plants requires that dams are monitored by means of tools for assessing the safety and ensure the operation of power generation. Usually a large dam has hundreds or even thousands of instruments that measure various quality characteristics of the dam. Evaluate the results of measurements instrumentation of a large number of instruments 
DOI: 10.14807/ijmp.v7i1.369

individually may be impractical or even lead to high false alarms and discredit the monitoring system.

It should be given continuous attention to operation and maintenance of the safety of a dam power plant. The tool for this is the instrumentation of the dam. Due to the particularities of each hydropower plant, there are no universal procedures applicable to all dams in respect to the evaluation of the instrumentation. The evaluation and judgment of information available for an experienced engineering team is the best way to contribute to a decision and choose the best action to be implemented (USACE, United States Army Corps of Engineers, 1995).

The main sources of variability of the readings of instruments for monitoring dams are attributed to temperature, reservoir level and aging (ROSSO et al., 1995), (ITAIPU BINACIONAL, 1999; CHENG; ZHENG, 2013; NEDUSHAN, 2002).Two models were created to relate the effects of instrument readings and environmental variables in a dam of China. The methods showed ability to reduce the rate of false alarms and detect defective instruments (CHENG; ZHENG, 2013).

Diagnosed singular values in monitoring dam safety, with a case study on the hydroelectric plant in China, via multivariate analysis of principal components and graphic control Hotelling $T^{2}$ (GU et al., 2011). In a hydroelectric power in China it was applied a model that extracts principal components of data instrumentation and establish a seasonal hydrostatic in time model between the variables reservoir level, temperature and time effects and principal components (YU et al., 2010).

Techniques for detection of structural damage are proposed using nonlinear principal component analysis and auto-associative neural network method to data monitoring in an arch dam caused by varying environmental conditions through the statistical analysis threshold level for early warning on dam static deformation can be determined (LOH; CHEN; HSU, 2011). The PCA, $Q$ and $T^{2}$ statistics are used to detect and distinguish damages in steel plates and turbine blades plane where vibrations caused are measured by sensors attached to the surface (MUJICA et al., 2011).

In the dam instrumentation, control values are those closer to the physical reality, considering the thermal environmental influences that act on structures and more realistic rheological models of concrete and foundation. Control values are 
DOI: 10.14807/ijmp.v7i1.369

used to monitor the performance of the structures by means of readings taken and are warning signs for abnormal situations of structural behavior. Values that were determined earlier in the design phase and the filling of the reservoir are not, in many cases, more applicable during the operation phase (ITAIPU BINACIONAL, 1999). It is necessary to establish operational control values for the instrumentation of hydroelectric plants.

This article aims to propose a multivariate statistical model for monitoring instruments for monitoring dams via control charts and principal components analysis and seeks to separate the effect of environmental variables on the reading of instruments from other sources of variability by use of statistics $T^{2}$ and $Q$ and establish control values for monitoring future observations. The method is evaluated in a case study applied to real data from monitoring a dam hydroelectric plant.

The article presents in section 2 the theoretical basis of knowledge of control charts and statistics to be used in this work and the place where the case study was applied and its significance. The section 3 describes the data and methods used in the developed model. Section 4 presents and discusses the results of a case study. In the section 5 some conclusions and considerations are presented.

\section{MULTIVARIATE CONTROL CHARTS}

\section{1. $T^{2}$ control charts}

The field of multivariate analysis consists of statistical techniques that consider two or more random variables related to a single entity in an attempt to produce an overall result that takes into account the relationship between the variables (JACKSON, 1991).The multivariate process control is a methodology based on control charts used to monitor the stability of a multivariate process. Stability is achieved when one or more parameters of interest remain stable on samples (MASON; YOUNG, 2002).

One of the first studies to examine correlated variables from the perspective of statistical control using multivariate procedures for military purposes was given by Hotelling (HOTELLING, 1947). This control procedure was based on a statistic that generalizes the Student $t$ statistic which later received the name of Hotelling $T^{2}$.

The application of univariate control charts can lead to erroneous and misleading interpretations and that multivariate methods are a good alternative 
DOI: 10.14807/ijmp.v7i1.369

(MONTGOMERY, 2013; JOHNSON; WICHERN, 2007). If the variables are correlated increases the probability of emission of false alarms and not to receive an alert when the multivariate process is out of control (RYAN, 2011).

Let be $m$ samples of $p$ variables, extracted for evaluation, of a process under control, of size $n=1$, represented by $\underline{\boldsymbol{x}}_{1}, \underline{\boldsymbol{X}}_{2}, \ldots, \underline{\boldsymbol{X}}_{m}$, where $\underline{\boldsymbol{X}}_{t}^{t}=\left(\boldsymbol{X}_{i 1}, X_{i 2}, \ldots, X_{i p}\right)$, with $i=\mathbb{1}_{1} 2_{\mathrm{r}} \ldots m$, taken from a $p$-variate normal distribution, with mean $\underline{\mu}$ and covariance matrix $\Sigma$. (MASON; YOUNG, 2002; MONTGOMERY, 2013). At almost always $\Sigma$ and $\underline{\mu}$ are unknown and in the practice are estimated, respectively, by unbiased estimators $\underline{\bar{x}}$, the sample mean and the positive definite matrix $S=\left(s_{i j}\right)$, where

$$
\begin{gathered}
\underline{\boldsymbol{X}}=\frac{1}{m} \sum_{i=1}^{m} \underline{\boldsymbol{X}}_{t} \\
S=\frac{1}{m-1} \sum_{i=1}^{m}\left(\underline{\boldsymbol{X}}_{t}-\underline{\boldsymbol{X}}\right)\left(\underline{\boldsymbol{X}}_{t}-\underline{\boldsymbol{X}}\right)^{t}
\end{gathered}
$$

and $s_{i j}$ is the covariance between variables $i$ and $j$. Multivariate statistical generalization of $t^{2}$ is the statistic called the Hotteling $T^{2}$ or, only, $T^{2}$, measuring the distance from an observation vector $\underline{\boldsymbol{X}}$ to the mean vector $\underline{\bar{X}}$ weighted by the covariance matrix $s$ and is given by

$$
T^{2}=(\underline{x}-\underline{\boldsymbol{X}})^{l}[S]^{-1}(\underline{\boldsymbol{X}}-\underline{\boldsymbol{X}})
$$

It is pointed to the existence of two phases in statistical quality control process. In the phase I (retrospective), the control limits are established and tested to the data available. It should be under levels considered statically under control. In the second phase (perspective) control limits are established from the same preliminary data and are used to monitor future data (MONTGOMERY, 2013; RYAN, 2011).

In the case of reading instrumentation monitoring of dams, which will be of interest in this work, the value of the $T^{2}$ statistic evaluated in $\underline{X}$ in the phase I by (Montgomery, 2013), (JOHNSON; WICHERN, 2007; RYAN, 2011), where a vector observation $\underline{X}$ is not independent of the estimators $\underline{\bar{X}}$ and $s$, is given by equation (3). The upper control limit (UCL) in the case of $n=1$, is recommended to be calculated based on a beta distribution (MASON; YOUNG, 2002), in this case

$$
U C L_{T^{2}}^{E}=\frac{(m-1)^{2}}{m} \beta_{\frac{2 m-p-1}{2}-1-\alpha}
$$


DOI: 10.14807/ijmp.v7i1.369

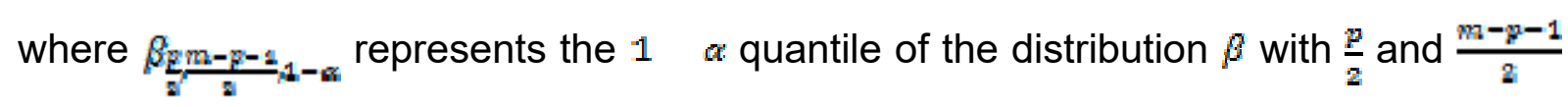
degrees of freedom. The upper control limit (UCL) of phase II, when the parameters are estimated in a previous sample and a vector observation $\underline{\boldsymbol{X}}$ is independent of the estimators $\underline{\bar{X}}$ and $S$, is given by

$$
\text { UCE } \tau_{T^{n}}^{L L}=\left[\frac{p(m \mid 1)(m-1)}{m(m-p)}\right] F_{p, m-p, 1-\alpha}
$$

where $F_{p, m-p, 1-\alpha}$ represents the $1-\alpha$ quantile of the $F$ distribution with $p$ and $m-p$ degrees of freedom. The $p$ dimensional ellipsoid $100(1-\alpha) \%$ prediction of a future observation is given by all vectors $\underline{X}$ satisfying

$$
(\underline{X}-\underline{\boldsymbol{X}})^{\prime}[S]^{-1}(\underline{X}-\underline{\boldsymbol{X}}) \leq u C L_{\tau^{2}}^{u}
$$

where $m$ is the number of samples (time).

An important issue in the treatment process with individual observations is the way of estimating the covariance matrix. The usual estimator is given by equation (2), however, there are various ways to estimate the covariance matrix, for example, the covariance matrix estimated by successive differences, is given by

$$
s_{D}=\frac{1}{2(m-1)} \sum_{i=2}^{m}\left(\underline{X}_{t}-\underline{X}_{t-1}\right)\left(\underline{X}_{t}-\underline{X}_{t-1}\right)^{t}
$$

This matrix was proposed by (HOLMES; MERGEN, 1993) and (CHOU; MASON; YOUNG, 1999) made a comparison between five types of covariance matrix estimates and showed that the common estimator $S$ is preferred for outliers detection.

\subsection{Principal components analysis (PCA)}

When the number of variables to be analyzed increases, the parameter that evaluates the average number of samples required to detect changes in the process is deteriorated, in this way, if suspected that the process variability is not equally distributed among all variables, it is useful to use other methods (MONTGOMERY, 2013).

Techniques 'reduction' data are based on the principle of creating sets of latent variables that capture the significant variation 'hidden' in the data. The change that the sets of latent variables extract of the process variables is of fundamental 
DOI: 10.14807/ijmp.v7i1.369

importance for the evaluation of product quality, process security and, more generally, if the process is in statistical control (KRUGER; XIE, 2012).

A method which can extract features in the data can be useful in dam safety study. As the instrumentation readings are a result of the combination of several factors, methods of multivariate data analysis can provide the following advantages: 1) more profitable by reducing the number of individual analysis, 2) greater ability to explain and separate the variability due to one because of random variability attributable since the random variabilities are, by definition, uncorrelated from one instrument to another and 3) to identify patterns of behavior (NEDUSHAN, 2002).

The PCA is a multivariate data analytical technique in which a number of related variables are transformed into a set of uncorrelated variables that are linear combinations of the original variables, where it is expected to explain the variability between variables with a smaller number of variables (JACKSON, 1991).

Its industrial application has contributed to the multivariate statistical process control, since only a few of multivariate control charts can serve as an index of process performance. PCA improves the early detection of failures in relation to the univariate graphs (KOURTI, 2005).

The eigenvectors of the covariance matrix form the columns of the orthogonal matrix $U$ the spectral decomposition of $s$, so that

$$
U^{t} S U=L
$$

where $L$ is a diagonal matrix of eigenvalues representing the variance of each principal component (JACKSON, 1991). Therefore, one can transform $p$ correlated variables $x=\left(x_{1}, x_{2}, \ldots, x_{p}\right)$ in $p$ new uncorrelated variables $z=\left(z_{1}, z_{2}, \ldots, z_{p}\right)$ through the transformation

$$
z=U^{r} x
$$

Is also true that

$$
x=U z
$$


DOI: 10.14807/ijmp.v7i1.369

However, when using a number $k<p$ principal component, then takes the sub-matrix of order $p \times k$ of $U$ and the sub-vector of order $k \times 1$ in product $U z$, yielding an approximation to $x$ will be represented by $\hat{x}$.

There is no consensus in the literature regarding the amount and the criteria for determining the number of components to be retained. A series of criteria for choice is presented in Jackson (1991), in this work the choice was based on the percentage of variance explained and the ability to detect out of the limit values as compared with the $T^{2}$ control chart. Here, this choice is relativized because the not retained components will also be evaluated on the $Q$ statistic.

The fact that the PCA produce independent variables have the advantage of making it possible to compare the false alarm rate of statistical control procedures of multivariate quality with univariate procedures such as Shewhart charts, because, according Montgomery (2013), the true probability type I error, if the variables are independent to the set control procedure is $\alpha^{t}=1-(1-\alpha)^{9}$, where $p$ is the number of variables and there is no closed formula otherwise.

\subsection{Regression analysis for missing data}

When working with large databases is relatively common not to have all the desired data. There are several reasons for this fact. In the case of automatic data acquisition, electronic problems could cause the loss or unreliability in receiving the information. In the case of non-automated acquisition, there may be several forms of human errors that cause no part of the data to be evaluated.

In multivariate case, it is suggested that missing data for a variable are obtained by using a regression procedure, e.g. linear, in which the variable with missing data is regressed on the other variables. A model of least squares can be used for the parameters of the variables in the linear prediction model (MASON; YOUNG, 2002).

Another way to treat this problem is given by the regression and time series forecasting established by well-known methodology of Box \& Jenkins. The ARIMA (auto regressive integrated moving average) models can be used to model time series data that has, making future predictions and cover missing data (BOX; JENKINS; REINSEL, 2008). In general ARMA models $(p, q)$ has the form 
DOI: 10.14807/ijmp.v7i1.369

$$
z_{i}=\phi_{1} z_{i-1}+\phi_{2} z_{i-2}+\cdots+\phi_{p} z_{i-\psi}+a_{i}-\theta_{1} a_{i-1}-\theta_{2} a_{i-2}-\cdots-\theta_{i q} a_{i-q} .
$$

A measure of the suitability of a model to a time series is given by measuring the mean square error (MSE), given by

$$
M S E=\frac{\sum_{i=1}^{n}\left(y_{t}-y_{i}\right)^{2}}{n-r-1}
$$

where $y_{i}$ is the observed value, $y_{i}$ is the predicted value, $n$ is the number of observations and $x-p+q+c^{r}$ is the number of parameters of the AREMA model or the number of independent variables used in the linear regression model.

\subsection{The $Q$ statistic}

When is formulated a model of the principal components in which the projection data has been standardized, an observation, consisting of a vector $\boldsymbol{x}$ of $p$ variables, can be write as $x=U_{\boldsymbol{z}}$, if not taken all principal components, has only an approximation $\mathrm{x}=\mathbb{Z}$, so that

$$
x=02+\left(x-\frac{x}{x}\right) .
$$

The first term on the right side of the equation (13) represents the contribution of $k(k<p)$ principal component and the second term the amount that is not explained by the principal component model, the residual. There are two types of outliers associated with each of these terms, the first term of an outlier that would be detected even if the principal component model was not applied and the second term indicates that an outlier any observation vector that cannot be adequately characterized the subset of principal components chosen (JACKSON, 1991). The $Q$ statistic is defined by

$$
Q=(x-\not)^{t}\left(x-x^{2}\right)
$$

$Q$ is also sometimes known by $S P E$ (squared prediction error). A preview of the vector $\left(x-x^{2}\right)$ in the space of principal components in relation to the space of components retained is seen in the Figure 1.This statistic represents the changes that are not explained by the principal component model. It is a measure of the difference between the sample mean and its projection on the PC model (MUJICA et al., 2011). 


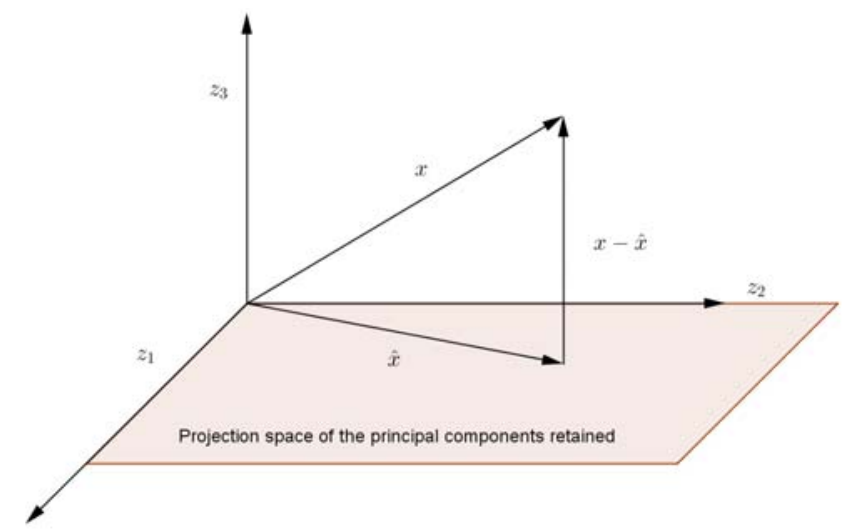

Figure 1: Geometric interpretation of the residual vector in the space of principal components.

The upper control limit of $Q$, denoted by $Q_{\alpha}$, according Mudholkar and Jackson (1979) is

$$
Q_{\alpha}=\theta_{1}\left[\frac{z_{\alpha \alpha} \sqrt{2 \theta_{2} h_{0}^{2}}}{\theta_{1}}+\frac{\theta_{2} h_{0}\left(h_{0}-1\right)}{\theta_{1}^{2}}+1\right]^{1 / h_{0}}
$$

where $z_{\alpha}$ is the value that corresponds to $100(1-\alpha)$ percentile of the standard normal distribution, $\alpha$ is the probability of type I error (will be fixed at 0.0027 here) and

$$
\theta_{i}=\sum_{i=k+1}^{p} l_{j}^{t}
$$

for $t=1,2,3, l_{\imath}$ is the $i^{\text {th }}$ eigenvalue of the covariance matrix and

$$
h_{0}=1-\frac{2 \theta_{1} \theta_{\mathrm{a}}}{3 \theta_{2}^{2}}
$$

\subsection{The Itaipu dam and the importance of instrumentation}

Recently, in May 2014, the Binational Itaipu Dam, located on the Paraná River between Brazil and Paraguay, completed 30 years since the beginning of the generation and the world leader in production of clean and renewable energy. Itaipu is responsible for producing $17 \%$ of electricity in the Brazilian market and $75 \%$ of the Paraguayan market (JORNAL INTERNO DE ITAIPU, 2014). In 30 years of operation, Itaipu has generated 2:16 billion MWh, enough to supply the entire world for 36 days and Brazil for almost five years energy. 
DOI: 10.14807/ijmp.v7i1.369

Itaipu is currently the second largest dam in the world in installed capacity, $14,000 \mathrm{MW}$ in 20 generating units, overcome by Three Gorges Dam in China which

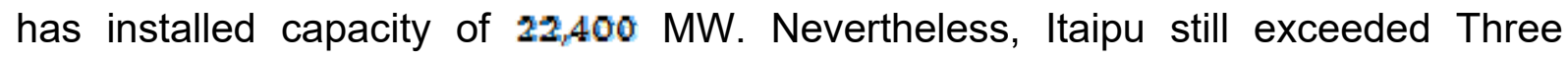
Gorges in annual energy production until 2013 (JORNAL INTERNO DE ITAIPU, 2014; GAZETA DO POVO, 2014; GLOBO, 2014).

To maintain these important economic numbers from the point view of environmental issues and the impact on the entire community that is close not only to the dam, but also to the entire area of the reservoir, it is necessary to ensure that the behavior of the structures is under control.

In countries where hydropower potential has been exploited extensively, this development started over $\mathbf{5 0}$ years ago and many dams are aging and it is necessary to maintain the security conditions which may prevent costly repairs and that are often conflicting with the production of energy (XXIII INTERNATIONAL COMITEE OF LARGE DAMS, 2009). The improvement of dams not only ensures the safe operation and performance, but also improves its efficiency (XXIII INTERNATIONAL COMITEE OF LARGE DAMS, 2009).

The dams should have adequate instrumentation for monitoring their performance. The goal is to control the operation of the dam safely under any condition. The instrumentation shall allow the measurement of the structural behavior and the physical condition of the dam (USACE, UNITED STATES ARMY CORPS OF ENGINEERS, 1995).

\section{DATA AND METHODS}

This work was developed with real data from the instrumentation section $E$ the Itaipu hydroelectric plant, shown in Figure 2. Faced with various instruments present, the piezometers were chosen because of the amount and the importance of their role in measuring uplift pressures in the dam.

The $E$ section has seven piezometers. As the frequency of readings from the period of reservoir filling in 1994 varied, was chosen to analyze the period from 2001 until 2013 when the readings were approximately biweekly for all piezometers. This period generated 319 readings for each instrument from now on called piezometers $P_{1}, P_{2}, \ldots, P_{7}$. 
DOI: 10.14807/ijmp.v7i1.369

The reading of each piezometer is an independent and identically distributed random variable. For phase I, the adjustment test (retrospective) of the model, were selected 300 readings and for Phase II validation (perspective) of the model, we selected the remaining 19 readings. It is important to mention that in this phase I data are considered under the control of a statistical point of view. The instrument $P_{2}$ had some missing data during the phase I. In this way, the linear and by time series regressions were applied and the MSE equation (12) was used to choose the best model for filling the missing data.

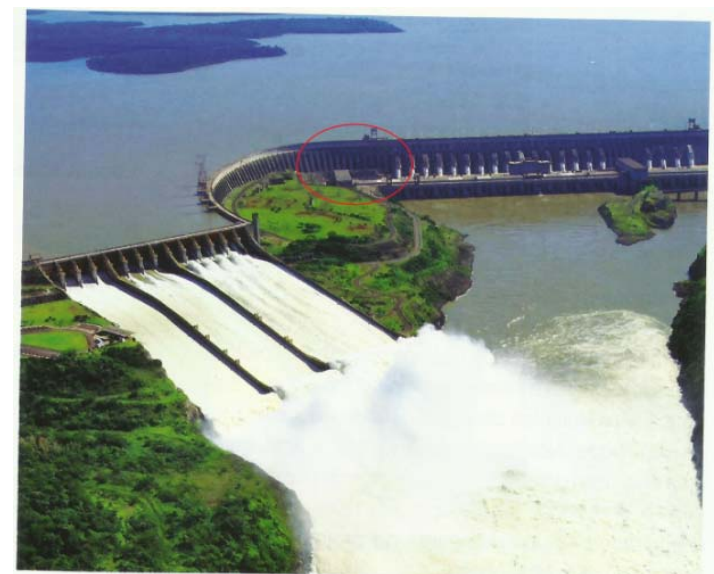

Figure 2: Dam of Itaipu and section E featured.

Variables that are in very different scales and domain variation should be standardized (JOHNSON; WICHERN, 2007). The reason for this procedure is that the original variables can have scales and domain quite distinct giving false interpretation of its real magnitude variability, which is avoided by standardizing (MONTGOMERY, 2013).

The steps of the method consist of:

- Gathering and data standardization;

- Prediction of missing values;

- Test the multivariate normality;

- Choosing the Type I error probability and the estimate of the covariance matrix;

- Construct the graphic $T^{2}$ for the full set of variables; 
DOI: 10.14807/ijmp.v7i1.369

- Extraction and selection of the number of principal components and normality test;

- Construction of the graph $T^{2}$ and the ellipse control of the principal components in phases I and II;

- Calculation of residual and $Q$ statistics;

- Construction of Q-chart;

- Interpretation of results.

\section{RESULTS}

Among the forecast models for missing data to $P_{2}$ was chosen a model ARIMA $(6,0,6)$ with $M S E-0.065$, the lowest compared to other ARIMA regression models and linear regression on the other variables to adjust 24 missing data

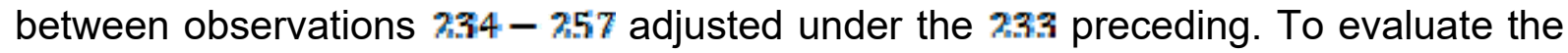
hypothesis of multivariate normality was used a test of adjustment $\chi_{p}^{2}$ described in Mingoti (2005) and Johnson and Wichern (2007). For each vector $X^{t}=\left(X_{1}, X_{2}, \ldots, X_{7}\right)$ containing the standard readings of piezometers was calculated

$$
(X-\bar{X}) S^{-1}(X-\bar{X}) \leq \chi_{F / \% \%}^{2}
$$

where $\chi_{5_{1}}^{2} \%_{6}$ corresponds to the $95 \%$ percentile of the distribution $\chi_{\%}^{2}$. Once exactly $95 \%$ of the first phase of the sample satisfied the condition, we can accept the hypothesis that the data come from a multivariate normal distribution at $95 \%$ confidence level.

For comparison, univariate charts Shewhart control of the sample mean $\bar{x}$ were built for phase I, $U C L E-\bar{x}+5 \hat{\theta}, L C L-\bar{x}-30$ e $\hat{O}$ is, according Montgomery (2013) an unbiased estimator for $\sigma$, given by $\bar{\delta}=\bar{R} / d_{2}$, where $\bar{R}$ is the average amplitude and $d_{2}=1.12 R$, so that the false alarm rate is $\alpha=0.27 .7 \%$. The Table 1 shows the number of observations outside the control limits $(\mathrm{OCL})$ to univariate Shewhart charts respective of $P_{1}$ to $P_{7}$ instruments to 300 data of phase I. Note the impossibility of univariate treatment with the high number of observations OCL.

To select the estimator covariance matrix to be used in $T^{2}$ chart for the data on the seven standard piezometers were tested usual covariance matrix (2) and the 
INDEPENDENT JOURNAL OF MANAGEMENT \& PRODUCTION (IJM\&P)

http://www.ijmp.jor.br

v. 7, n. 1, January - March 2016

ISSN: 2236-269X

DOI: 10.14807/ijmp.v7i1.369

matrix successive differences (7). The Table 2 shows the number of observations outside the control limit (OCL) for $T^{2}$ chart for each type of tested covariance matrix for a type I error probability fixed at $\alpha=0.0027$ for every variable that corresponds the limits $3 c$ of Shewhart charts, then, according Montgomery (2013), the real probability of type I error if the variables are independent, for all control procedure is $\alpha^{t}=\mathbb{1}-(\mathbb{1}-\alpha)^{7}=0.0187$. It should be noted, of course, the original variables are not independent.

Nevertheless the multivariate treatment becomes feasible, since the probability that 8 or more observations in the universe of 300 are at random above $L S C_{T}^{2} \mathrm{~m}$ if the data originates a multivariate normal distribution is 0.2026 , for $\alpha^{t}=0.0187$, it cannot reject the hypothesis that the process is in statistical control at $95 \%$ confidence. Because the matrix (7) is more sensitive to small deviations from the mean, for the purpose of this study, the matrix (2) was selected.

Table 1: Observations outside the control limits (OCL) for univariate charts.

\begin{tabular}{llllllllllllll}
\hline Inst. & $O C L$ & Inst. & $O C L$ & Inst. & $O C L$ & Inst. & $O C L$ & Inst. & $O C L$ & Inst. & $O C L$ & Inst. & $O C L$ \\
\hline$P_{1}$ & 239 & $P_{2}$ & 178 & $P_{3}$ & 203 & $P_{4}$ & 82 & $P_{5}$ & 149 & $P_{6}$ & 190 & $P_{7}$ & 166 \\
\hline
\end{tabular}

Table 2: Number of observations (OCL) to each covariance matrix for the $T^{2}$ chart.

\begin{tabular}{llll}
\hline Matrix & $O C L$ & Observations & $U C L$ \\
\hline Usual & 8 & $25,68,249,250,264,268,269,270$ & \\
\cline { 1 - 3 } Successive Differences & 300 & \multicolumn{1}{c}{ All } & \\
\cline { 1 - 3 } & &
\end{tabular}

Extracting the principal components of the data set of phase I, a simulation was performed by selecting $k=2,3,4,5,6$ principal components that explain a percentage of variability as shown in Table 3.

Table 3: Variability explained by principal components.

\begin{tabular}{c|c|c|c}
\multirow{2}{*}{ Component } & \multirow{2}{*}{ Eigenvalue } & \multicolumn{2}{|c}{ Variability (\%) } \\
\cline { 3 - 4 } & & Explain & Accumulated \\
\hline 1 & 3.55585 & 50.80 & 50.80 \\
\hline 2 & 1.45125 & 20.73 & 71.23 \\
\hline 3 & 1.02258 & 14.61 & 86.14 \\
\hline 4 & 2.50179 & 7.17 & $93 . \Omega 1$ \\
\hline 5 & 0.26410 & 3.77 & 97.68 \\
\hline 6 & 2.13599 & 1,94 & 99.02 \\
\hline 7 & 2.0684 .5 & 0.98 & 100.00
\end{tabular}


INDEPENDENT JOURNAL OF MANAGEMENT \& PRODUCTION (IJM\&P)

http://www.ijmp.jor.br

v. 7, n. 1, January - March 2016

ISSN: 2236-269X

DOI: 10.14807/ijmp.v7i1.369

The eigenvectors of the matrix $U$ of the spectral decomposition of $S$ are shown in Table 4. Data from scores of $k$ principal components were retained and multivariate normality was tested by the test $\chi_{k}^{2}$ at a confidence level of $95 \%$ that obtained the acceptance of the hypothesis normality, according second column of Table 5.

Table 4: Eigenvectors of the sample covariance matrix S.

$\begin{array}{rrrrrrr}0.1029 & 0.6931 & 0.3506 & 0.4859 & 0.0651 & 0.3719 & 0.0939 \\ 0.3485 & -0.4289 & 0.1239 & -0.7007 & -0.3266 & 0.2820 & 0.0454 \\ 0.4481 & 0.3431 & 0.1700 & 0.1886 & 0.1189 & 0.5824 & -0.5135 \\ 0.1458 & -0.4160 & 0.7757 & 0.2213 & 0.3095 & -0.2426 & -0.0161 \\ 0.4588 & 0.1106 & 0.0659 & 0.4222 & -0.6996 & -0.2263 & 0.2324 \\ 0.1456 & 0.1774 & 0.41145 & 0.0887 & 0.1807 & 0.5500 & 0.1006 \\ 0.4867 & 0.0274 & -0.2342 & 0.0477 & 0.5036 & 0.1391 & 0.6574\end{array}$

Table 5: $T^{2}$ chart results of $k$ PC's obtained from the retention $k$ PC's.

\begin{tabular}{|c|c|c|c|c|c|c|c|c|c|c|}
\hline \multirow{2}{*}{$k$} & \multirow{2}{*}{$\%$} & \multirow{2}{*}{$\alpha^{s}(\%)$} & \multicolumn{4}{|c|}{ Phase I } & \multicolumn{4}{|c|}{ Phase II } \\
\hline & & & $U C L_{T}^{x}=$ & $\alpha C L_{T}^{2}$ & $O B S$ & Frub. & $U C L_{T^{2}}^{M}$ & $O C L_{T^{2}}^{Z 2}$ & $O B S$ & Fruét. \\
\hline 2 & $\$ 6.67$ & 0.539 & 10.30 & 0 & - & $100 \%$ & 10.44 & 0 & - & $100 \%$ \\
\hline 3 & $\$ \$, 00$ & 0.808 & 11.34 & 5 & $\begin{array}{c}249: 250269 \\
260,269\end{array}$ & $9.81 \%$ & 11.81 & 7 & $\begin{array}{c}249,250,260,269 \\
\$ 17,318, \$ 19\end{array}$ & $1.6 \%$ \\
\hline 4 & $\$ 6.00$ & 1.67 & 12.91 & 5 & $\begin{array}{c}249: 250269 \\
2602,265\end{array}$ & $22.58 \%$ & 13.12 & 7 & $\begin{array}{c}249,250,269,260 \\
269,318, \$ 19\end{array}$ & $0.01 \%$ \\
\hline 5 & $\$ 5.67$ & 1,34 & 14.15 & 7 & $\begin{array}{c}60,249,260 \\
269 ; 250,269,270\end{array}$ & $11.13 \%$ & 14.37 & 8 & $\begin{array}{l}50,279,262,269 \\
269,270,8: 0,519\end{array}$ & $6.78 \%$ \\
\hline 6 & 54,67 & $1,6 !$ & 15.35 & 7 & $\begin{array}{c}60,249,230 \\
264,250,269,270\end{array}$ & $21.21 \%$ & 15.60 & 8 & $\begin{array}{l}20,249,2 \mathrm{B2}, 204 \\
260,269,250,31 \mathrm{~g}\end{array}$ & $14.63 \%$ \\
\hline
\end{tabular}

For example, the upper control limit for statistical $T_{2}^{2}$ (scores of 2 PC's) in phase I was calculated from equation (4) and resulted in $U C L_{T^{N}}=10.30$ and all observations of this phase did not exceed the control limit. For phase II, the upper control limit of statistical $T_{2}^{2}$ calculated from equation (5) resulted $U C E_{7}=10.44$. For the remaining numbers of components upper control limits are in the fourth and octave column of the Table 5 . The fifth and ninth columns of Table 5 contain the number of observations outside the control limits $(O C E)$ for the phase I $\left(O C E_{\mathrm{T}}^{I}\right)$ and for the phase $\|\left(O C L_{T}^{L E}\right)$ and these observations $(O B S)$ are in the sixth and tenth column for $T_{k}^{2}$ charts in the phases I and II. Finally, seventh, and eleventh columns of Table 5 contain the probability that the amount of OCL obtained is in control statistical at $95 \%$, that is, values less than $5 \%$ should reject the hypothesis that the data are under control. 
DOI: 10.14807/ijmp.v7i1.369

If we use $k=2, \ldots, 6$ of the 7 principal components, then taking the sub-matrix of order $7 \times k$ of $U$ and the subvector of order $k \times 1$ in the product $U z$, yielding an approximation for $x$, denoted by $\hat{x}$, using the equations (8),(9) and (10). The value obtained for the upper control limit of statistical $Q$ using equations (16), (17) and (15) was $Q_{\alpha}-9.95$ when $k-2$, the others values of $Q_{\alpha}$ for $k-3, n, 6$ are in the second column of Table 6 . The remaining columns of Table 6 show the amount of $O C L_{i}$, $a \mathrm{FF}_{\mathrm{az}}$ and what are these observations.

Table 6: Results for $Q$ chart of the $p-k$ principal components.

\begin{tabular}{|c|c|c|c|c|c|}
\hline \multirow[t]{2}{*}{$k$} & \multicolumn{5}{|c|}{$Q$ chart of the $p-k$ PC's } \\
\hline & $Q_{\alpha}$ & $Q G_{L_{7}}$ & OBS. & $\theta c_{v_{n}}$ & GBS. \\
\hline 2 & 9.95 & 4 & $249,250,26 \varepsilon_{2}, 269$ & 4 & $249,250,263,269$ \\
\hline 3 & 4,41 & 2 & 25,264 & 2 & 25,264 \\
\hline 4 & 2.09 & 3 & $25,140,249$ & 3 & $25,140,249$ \\
\hline 5 & 2.96 & 1 & 25,138 & 2 & $25,138,310$ \\
\hline 6 & 2.39 & 4 & $25,51,135,170$ & 4 & $25,51,135,170$ \\
\hline
\end{tabular}

The control chart of statistical $T_{4}^{2}$ including the data of the two phases is shown in the Figure 3 and the Figure 4. displays the control of the ellipse $95 \%$ confidence data $T_{4}^{2}$ for the first two principal components, the point in red represents the single observation out of control, which is outside the ellipse control we take the components 2 and 3. These plots were constructed for $\alpha=0.0027$ and the usual covariance matrix, equation (2), at $95 \%$ confidence level.

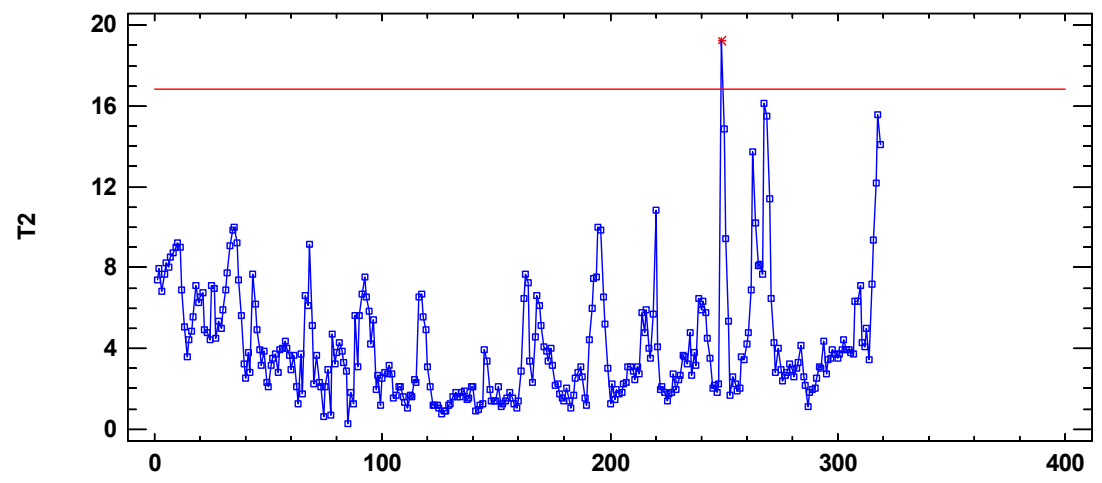

Figure 3: $T^{2}$ chart for 4 principal components retained in phases I and II. 


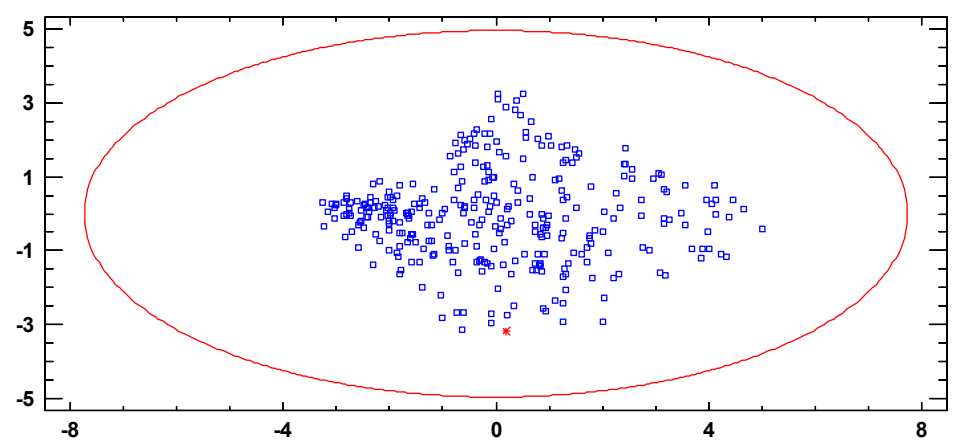

Figure 4: Ellipse control scores the first 2 components of 4 PC's retained.

The Figure 5 shows the behavior of the statistic $Q$ in the period of analysis, for $k=4$, calculated by equation (14).

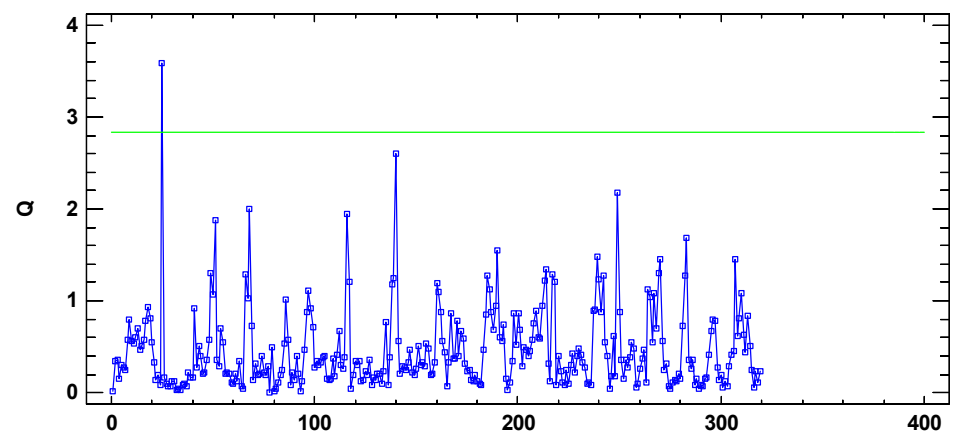

Figure 5: Values of the $Q$ statistic for $k=4$ principal components in the phases I and II.

\section{CONCLUSIONS}

This paper attempted to establish a method for dealing with control charts for dam monitoring instruments. In practice, given the large number of instruments in a large dam and the correlation between them, the individual monitoring of each instrument can be unfeasible, either by excessive graphics to analyze or the large number of false alarms that can discredit the system. The proposed method involves multivariate analyzes and summarizes the analysis of a set of instruments in the statistics $T^{2}$ and $Q$ combined with PCA for explaining, respectively, the inherent variability (assignable causes) and random sources in the system. The objective was to reduce the work using multivariate analysis, reducing false alarms to statistically under control levels and identify differences in observations outside the control limits for $T^{2}$ and $Q$ statistics.

Is worth mentioning that if it he had chosen to analyze seven Shewhart univariate charts for the mean and the $\pm 3 \&$ control limits would be obtained between 
DOI: 10.14807/ijmp.v7i1.369

82 and 239 values out of control (see Table 1) and the problem of establishing the limit values for instruments cannot be treated by this technique.

The results show that the principal components model combined with the $Q$ statistic best fit data of phase I when are taken, at least, four principal components, because in this case the observations listed as out of control to the $T^{2}$ chart appearing as out of control to the $T^{2}$ chart of $k$ principal components or $Q$ chart (compare Table 2, Table 5 and Table 6) and showed that, in the case study applied the multivariate monitoring of piezometers, located in section $E$ of the Itaipu hydroelectric plant, system is in statistical control at $\$ .5 \%$ confidence, independently of the contracted model, i.e., $T^{2}$ chart or principal components combined with $Q$ statistic.

Another benefit of the combined use of these statistics with 4 principal components was that the observations identified as out of control, one can make a distinction between them. Among the observations given as out of control for the $Q$ statistic for 4 PC's (see Table 6), observation 25 is related to the maximum global value of the instrument $p_{7}$, observation 140 is associated with the local maximum value in the instrument $p_{5}$ (both outliers are apparent) and observation 249 is associated with the global maximum of $p_{4}$ which is the instrument with smaller variance.

The adopted model enables an interpretation of the PC's as a consequent variability of environmental factors (inherent) to the model. It is essential to understand that the variability of the principal components is originated from these factors and also control the random variability that may be linked to outliers (2 statistic).

The use of principal components has another advantage which is to overcome the problem of singularities. In this case study, for example, the determinant of the covariance of all the original variables matrix was 0.0065 . The singularities are associated with the existence of eigenvalues near zero that can generate computational problems in the inversion of the covariance matrix and the consequent calculation of $T^{2}$ statistical.

The first four principal components explain more than $90 \%$ of the variability. It was observed that the first principal component has an interpretation in terms of an 
DOI: 10.14807/ijmp.v7i1.369

average contribution of each instrument for the overall variability and that this depends on the elevation layer and in which they are. According to the first column of Table 4 , it can be seen that the $p_{7}$ instrument is has the greatest contribution to this principal component and its location is before a concrete injection curtain and at a lower elevation, i.e., the local theoretically more susceptible to uplift pressures. The second instrument with greater contribution in this principal component $p_{5}$ is located in a joint with lower elevation, as shown in Figure 6 . Since the instrument that has almost no effect on this component is $p_{1}$ and its location is after injection curtain at the top elevation of instruments study. This confirms the efficiency of concrete injecting curtain at the dam.

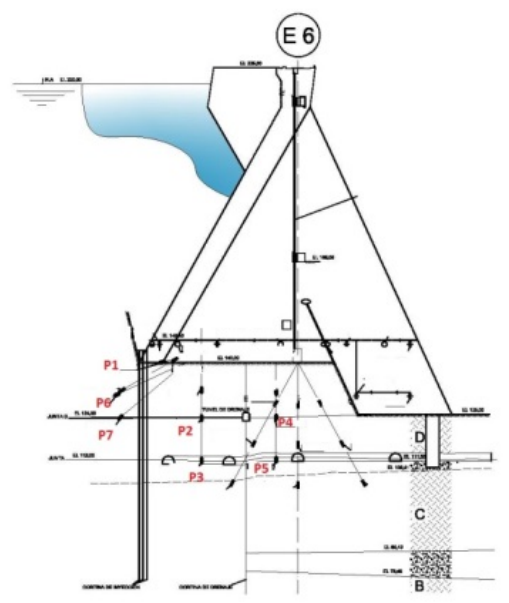

Figure 6: Piezometers in section E of Itaipu Dam Source: adapted from Itaipu Binational.

Suggestions for future work involving this type of approach may be the use of non-parametric statistics, the variation of the rate of false alarms $\alpha$ and the analysis of other instruments can also enable the discovery of new knowledge, as well as seek interpretation for other principal components.

Acknowledgements. The team CEASB - Advanced Center for Studies on Dam Safety, in the accord between Itaipu Binational and the Itaipu Technological Park, for the collaboration and reliance.

\section{REFERENCES}

BERSIMIS, S.; PSARAKIS, S.; PANARETOS, J. (2007) 'Multivariate statistical process control charts: an overview', Quality and Reliability engineering international, v. 23, p. 517-543, doi:10.1002/qre.829.

BOX, G. E. P.; JENKINS, G. M.; REINSEL, G. C. (2008) Time-series analysis - 
forecasting and control, $4^{\mathrm{a}}$ ed., Hoboken, New Jersey: John Wiley \& Sons, Inc.

CHENG, L.; ZHENG, D. (2013) 'Two online dam safety monitoring models based on the process of extracting environmental effect', Advances in Engineering Software, v. 57,pp. 48-56, doi:10.1016/j.advengsoft.2012.11.015.

CHOU, Y. M.; MASON, R. L.; YOUNG, J. C. (1999) 'Power comparisons for a Hotelling's T2 statistic', Commun. Statist. Simulation Comput., v. 28, p. 1031-1050, doi:10.1080/03610919908813591.

GAZETA DO POVO (2014) Gazeta do Povo, 08 Maio, [Online], Available: HYPERLINK www.gazetadopovo.com.br/economia/especial-itaipu-30anos/conteudo. phtml?tl=1\&id=1466225\&tit=Gigante-pela-propria-natureza [08 Maio 2014].

GLOBO (2014) G1 Globo, [Online], Available: HYPERLINK www.g1.globo.com/pr/oeste-sudoeste/noticia/2014/05/seria-inimaginavel-o-paraguaie-o-brasil-sem-itaipu-diz-diretor-geral.html [08 maio 2014].

GU, C. S.; ZHAO, E. F.; JIN, Y.; SU, H. Z. (2011) Singular value diagnosis in dam safety monitoring effect values, Sciencie China Technological Sciences, v. 54, n. 5, May, p. 1169-1176, doi 10.1007/s11431-011-4339-7.

HOLMES, D. S.; MERGEN, A. E. (1993) Improving the performance of the T2 control chart, Quality Engineering, v. 5, n. 4, March, p. 619-625,

DOI:10.1080/08982119308919004.

HOTELLING, H. (1947) Multivariate quality control, Techniques of statistical analysis, p. 111-184.

ITAIPU BINACIONAL (1999) Estudos para a reavaliação dos valores de controle para a instrumentação civil das estruturas e fundações (2660.50.15402.P), Foz do Iguaçu.

ITAIPU BINACIONAL (1999) Estudos para a reavaliação dos valores limites para a instrumentação civil das estruturas e fundações (2662.50.15401-P), Foz do Iguaçu.

JACKSON, J. E. (1991) A user's guide to principal components, New York: John Wiley \& Sons, Inc.

JOHNSON, R. A.; WICHERN, D. W. (2007) Applied Multivariate Statistical Analysis, 6th. ed., Upper Saddle River - NJ: Pearson Prentice Hall.

JORNAL INTERNO DE ITAIPU (2014) JIE, 08 maio, [Online], Available:

HYPERLINK jie.itaipu.gov.br/index.php?secao=noticias_itaipu\&q=node/6\&pagina $=4$ [08 maio 2014].

KOURTI, T. (2005) Application of latent variable methods to process control and multivariate statistical process control in industry, International Journal of adaptive control and signal processing, v. 19, p. 213-246, doi: 10.1002/acs.859.

KRUGER, U.; XIE, L. (2012) Statistical monitoring of complex multivariate process with applications in industrial process control, Chichester: John Wiley \& Sons.

LOH, C. H.; CHEN, C. H.; HSU, T. Y. (2011) Application of advanced statistical methods for extracting long-term trends in static monitoring data from an arch dam, 
DOI: 10.14807/ijmp.v7i1.369

Structural Health Monitoring, v. 10, n. 6, November, p. 587-601, doi: 10.1177/1475921710395807.

MASON, R. L.; YOUNG, J. C. (2002) Multivariate statistical process control with industrial applications, Philadelphia - Pennsylvania: ASA SIAM - American statistical Association - Society for industrial and applied mathematics.

MINGOTI, S. A. (2005) Análise de dados através de métodos de estatística multivariada: uma abordagem aplicada, Belo Horizonte: UFMG.

MONTGOMERY, D. C. (2013) Introdução ao Controle Estatístico de Qualidade, $4^{\text {th }}$ edition, Rio de Janeiro: LTC.

MUDHOLKAR, G. S.; JACKSON, J. E. (1979) Control procedures for residual associated with principal components analysis., Technometrics, v. 21, n.3, August, p. 341-349.

MUJICA, L. E.; RODELLAR, J.; FERNÁNDEZ, A.; GUEMES, A. (2011) Q-statistic and T2 statistic PCA-based measures for damage assessment in structures, Structural Health Monitoring, v. 10, n. 5, September, p. 539-553, doi: 10.1177/1475921710388972.

NEDUSHAN, B. A. (2002) Multivariate statistical analysis of monitoring data for concrete dams, Montreal: PhD Thesis, McGill University - Department of Civil Engineering and Apllied Mechanics.

ROSSO, J. A.; FIORINI, A. S.; PORTO, E. C.; SILVEIRA, J. F. (1995) Barragem de Itaipu - Lições aprendidas com o comportamento térmico das estruturas tipo gravidade aliviada e contraforte, XXII Seminário Nacional de Grandes Barragens, São Paulo.

RYAN, T. P. (2011) Statistical Methods for Quality Improvement, John Wiley \& Sons.

USACE, UNITED STATES ARMY CORPS OF ENGINEERS (1995) Enginnering and Design - Instrumentation of Embankment Dams and Levees, Washington, DC.

XXIII INTERNATIONAL COMITEE OF LARGE DAMS (2009) Hydropower current developments - Question 88, Dams and Hydropower, Brasília, 6-8.

XXIII INTERNATIONAL COMITEE OF LARGE DAMS (2009) Question 90, Upgrading of existing dam, Brasília, 7.

YU, H.; WU, Z. R.; BAO, T. F.;ZHANG, L. (2010) Multivariate analysis in dam monitoring data with PCA, Sciencie China Technological Sciences, v. 53, n. 4, April, p. 1088-1097, doi: 10.1007/s11431-010-0060-1. 